\title{
Performances of a Bitumen Fume and Condensate Generation System for Sampling Method Development
}

\author{
Benjamin Sutter, Eric Pelletier, Christel Ravera, Eddy Langlois \\ Pollutants Metrology, Institut National de Recherche et Sécurité, Vandoeuvre-Les-Nancy, France \\ Email: benjamin.sutter@inrs.fr
}

Received 2 May 2016; accepted 3 June 2016; published 6 June 2016

Copyright (C) 2016 by authors and Scientific Research Publishing Inc.

This work is licensed under the Creative Commons Attribution International License (CC BY).

http://creativecommons.org/licenses/by/4.0/

(c) (i) Open Access

\begin{abstract}
A laboratory system was designed to generate bitumen fumes and expose tested samplers in a homogenised chamber. The system was also designed to condense the fumes in the form of oil that could be used as a standard for further analytical method development. The laboratory system was evaluated in terms of stability, repeatability, aging, and ranges, focusing on the quality and quantity of the fumes and their physical characteristics. The fumes generated with the laboratory system were also compared to fumes emitted at workplaces to evaluate their similarity. The results demonstrated that laboratory fume generation was stable and repeatable. Humidity ranged from $20 \%$ to $80 \% \mathrm{RH}$ and the total fume concentration ranged from 0.01 to $9.36 \mathrm{mg} \cdot \mathrm{m}^{-3}$, covering the conditions encountered for road paving worksites. The fumes generated in the laboratory were found to be similar to those of workplaces, with slight differences in light compounds equivalent to $\mathrm{C} 12$ and below n-alkanes. Thus, the system designed in this study is considered capable of generating bitumen fumes used to develop sampling and analysis methods.
\end{abstract}

\section{Keywords}

Bitumen, Fumes, Laboratory Generation, Condensate Generation, Road Paving

\section{Introduction}

Occupational exposures to straight-run bitumens and hard bitumens and their emissions are classified 2B by the International Agency for Research on Cancer (IARC) and 2A for oxidized bitumens and their emissions [1]. However, the carcinogenic effect of the fumes is not the only one. The irritant effect on the respiratory tract and mucous membranes was identified by the National Institute for Occupational Safety and Health (NIOSH) and 
the American Conference of Governmental Industrial Hygienists (ACGIH) [2] [3] as that being most prevalent on workers. Consequently, the ACGIH defined a Threshold Limit Value (TLV) of $0.5 \mathrm{mg} \cdot \mathrm{m}^{-3}$ of cyclohexane extractible organic matter collected by a filter, for which the occurrence of irritant effects on the workers is prevented.

A new strategy has been applied in France since 2013 to assess the exposure of workers to fumes from road paving construction sites using straight-run bitumens and hard bitumens, to take into account the conclusions of NIOSH and ACGIH. The quantification of Polycyclic Aromatic Compounds (PACs) and specifically benzo[a]pyrene was replaced by the determination of the total organic compounds responsible for the irritant effect. Thus the French strategy is now consistent with the German one in application since the publication of IFA method No. 6305 [4] in 2008.

Consequently, a new method for sampling and analysing bitumen fumes was needed in France. As bitumen fume emission depends on numerous environmental parameters in view to developing sampling and analysis methods according to standards EN 482:2012 and EN 13936:2012 [5] [6], it was necessary to generate fumes under controlled laboratory conditions to assess the behaviour of the sampling train and determine the global performance of a new method set up. Thus a bitumen fume generator was designed to expose personal samplers to control bitumen fumes. The generation system was also designed to produce bitumen fume condensates in view to using it as a standard for further developments of the analytical method.

The aim of this work was to characterize the laboratory bitumen fume generation system developed, which should produce fumes similar to real worksite fumes with respect to total organic matter quantification. In the first step, generation parameters such as temperatures, humidity, granulometry, particles and vapour concentrations were checked to assess stability, homogeneity, repeatability and aging. Then, the fumes generated in the laboratory were compared to real road paving worksite samples to evaluate the capacity of the system design to produce similar bitumen fumes in the laboratory. Finally, the similarity of the condensate produced by the condensation system was evaluated by comparing a condensate produced in the laboratory with field samples.

\section{Materials and Method}

Fume generation for sampler exposure and condensate generation differs according to the design of the system used. Two configurations are described in detail below. The generation chamber was the common part used for both fume and condensate generation.

\subsection{System Design for Sampler Exposure to Humidified Bitumen Fumes}

The exposure chamber and the humidity generator were placed at the outlet of the generation chamber. Figure 1 is a schematic representation of the overall system used for sampler exposure. This system is based on the system originally used in a previous toxicological study [7] and was modified to comply with the aims of this present study.

The generation chamber consists of a metallic vessel containing liquid bitumen connected at the bottom of a square chamber from which fumes are emitted and aged before injection into the exposure chamber.

The vessel is a cylinder $170 \mathrm{~mm}$ in diameter and $180 \mathrm{~mm}$ in height which contains 3 litres of bitumen. The temperature of the bitumen is regulated at $170^{\circ} \mathrm{C}$ with a Proportional-Integral-Derivated controller loop connected to a Pt100 probe immerged in the liquid bitumen and a hotplate in contact of the bottom of the vessel. The bitumen is continuously stirred at $160 \mathrm{rpm}$ during heating in order to homogenise the temperature and the composition of the liquid bitumen. Leaks between the vessel and the chamber are prevented by a Viton ${ }^{\circledR}$ gasket.

The chamber has a cubic shape of $260 \mathrm{~mm}$ width and depth and a height of $470 \mathrm{~mm}$. Dry air is blown inside the chamber over the surface of the hot bitumen, with a flow $Q_{f}$ regulated by a Brooks ${ }^{\circledR}$ mass flow controller noted Mass Flow Controller 3, ranging from 0.2 to $20 \mathrm{Nl} \cdot \mathrm{min}^{-1}$. The average residence time of the fumes inside the chamber is estimated at $3.01 \mathrm{~min}$ at a $Q_{f}=2 \mathrm{l} \cdot \mathrm{min}^{-1}$ with the Residence Time Distribution (RTD) method. As the geometric residence time has a value of $16.02 \mathrm{~min}$, longer than the average residence time, this indicates that there is a dead volume inside the generation chamber. This means that the fumes generated at the surface of the bitumen are transferred almost directly through the exposure chamber with a younger age than expected theoretically, provided the chamber is perfectly homogenized.

The relative pressure inside the generation chamber is measured by an Almemo ${ }^{\circledR}$ sensor (ref. FDA602S2K, Ahlborn, Germany) while a PT100 thermocouple (ref. Almemo ${ }^{\circledR}$ ZA9030-FS1, Ahlborn, Germany) is used for 


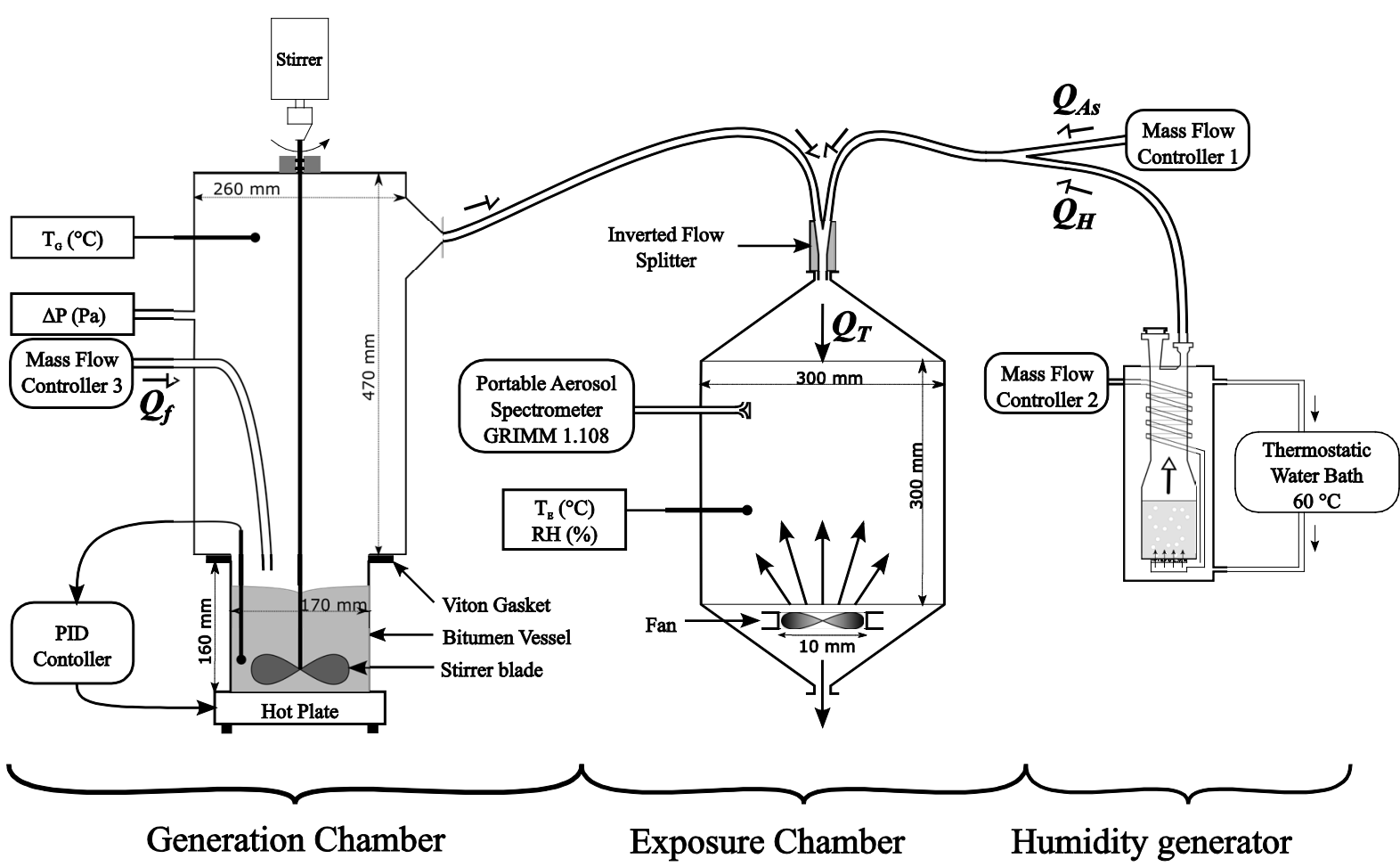

Figure 1. Schematic representation of the fume generation system used for the exposure of the samplers.

the bitumen temperature. The temperature of the fumes is measured with an independent PT100 thermocouple at the top of the chamber to check stability.

Bitumen fume concentrations in the generation chamber exceeded $50 \mathrm{mg} \cdot \mathrm{m}^{-3}$, whatever the bitumen studied. Therefore, to produce concentrations from 0.1 to $20 \mathrm{mg} \cdot \mathrm{m}^{-3}$, these fumes are diluted by humidified clean air, a mixture of dry and humidified clean air.

The humidifier bubbles dry air through demineralised water maintained at $60^{\circ} \mathrm{C}$ to ensure that the air injected is rapidly saturated with water. Mass flow controller (MFC) numbered 1 and 2 allows regulating the air humidity by changing the flow ratio between the dry air, noted $Q_{A S}$ (MFC 1 ) in Figure 1, and the humidified air, noted $Q_{H}$ (MFC 2) in Figure 1, keeping the sum constant.

The total flow injected in the exposure chamber, noted $Q_{T}$ in Figure 1, is constant, equal to the sum of $Q_{f}, Q_{A S}$ and $Q_{H}$ and fixed at $40 \mathrm{l} \cdot \mathrm{min}^{-1}$ for all generations. This ensures that the aeraulic conditions inside the exposure chamber remain constant for all the assays regarding the homogeneity of the fume concentrations and air speed, which affects the sampling efficiency of the samplers. Consequently, as a function of the concentration desired inside the exposure chamber, the conditions are adjusted to keep $Q_{T}$ constant.

The fumes and the clean humidified air are mixed together in a flow splitter (TSI, ref. 3708) positioned in reverse. This inverted flow splitter ensures minimum impaction of the airborne particles when mixing the flows.

The exposure chamber consists of a cube of sides $30 \mathrm{~cm}$, open at the top and the bottom placed on a square pyramid to propagate the flow in the entire section of the cube. Active homogenisation is ensured by a fan placed in the bottom part of the exposure chamber to circulate the aerosol inside the chamber. The RTD method applied to the generation and exposure chamber provides an average residence time of $4.4 \mathrm{~min}$. This implies that the average residence time of the exposure chamber is calculated at $1.4 \mathrm{~min}$. as the geometric residence time is $0.9 \mathrm{~min}$. Consequently, there is no dead volume inside the exposure chamber, but a small bypass can be observed. This means that a small fraction of the fumes could stay inside the chamber longer than the majority of the fumes, leading to the exposure of samplers to fumes of different ages. The effect of this bypass on the quality of the fumes is negligible due to its small size.

Temperature and relative humidity are measured by a single probe (Almemo ${ }^{\circledR}$ FHA646-E2C, Ahlborn, Germany), within the ranges of $-20^{\circ} \mathrm{C}$ to $80^{\circ} \mathrm{C}$ and $5 \%$ to $98 \% \mathrm{RH}$.

In this configuration, up to 12 samplers can be placed inside the chamber, fixed on 3 of its 4 walls. 


\subsection{System Design for Condensate Generation}

Calibrating analytical devices for bitumen fumes is a necessary stage for assessing the performances of analytical methods. Thus, a collection system was developed to collect particles and vapours produced in the generation chamber as a liquid condensate. Some studies have already developed such systems to produce more similar condensates that those that can be obtained on road construction sites [8] [9]. These condensation systems consist in, firstly, collecting particles on a filter, then condensing vapours on a cold trap and, finally, adsorbing the remaining vapours, the lighter ones, on an adsorbing bed of XAD-2 resin.

This fume collector is placed at the generation chamber outlet. Only flow $Q_{f}$ was changed from the range 0.2 - 2 $1 \cdot \mathrm{min}^{-1}$ to a fixed flow at $121 \cdot \mathrm{min}^{-1}$. The configuration of the condensation system is schematised in Figure 2 .

Fumes generated by the generation chamber pass through a first glass condensation tube, a filter, a second glass condensation tube, and a charcoal bed. Thus, the particle and vapour fractions of the fumes are collected. The glass condensation tubes are cooled to $-20^{\circ} \mathrm{C}$ by a circulating coolant fluid controlled by a thermostat. The glass condensation tubes have an inner diameter of $1 \mathrm{~cm}$ and a length of $40 \mathrm{~cm}$. Glass flasks collect the condensates produced on the cold surfaces of the glass condensation tubes. The filter is a Whatman, QM-A grade, nonwoven Quartz fibre filter, $37 \mathrm{~mm}$ in diameter (Whatman ${ }^{\mathrm{TM}}$, ref. 1851-037), which ensures high performance particle filtration and no interference with the organic compounds of the fumes collected. The filter is held by a $37 \mathrm{~mm}$ polypropylene cassette (SKC, ref. 225-8483), resistant to dichloromethane $\left(\mathrm{CH}_{2} \mathrm{Cl}_{2}\right)$ washing. Finally, the remaining lightest vapours are collected by $50 \mathrm{~g}$ of activated charcoal. An online valve linked to a vacuum pump is used to regulate the flow inside the condensation system, preventing overpressure from occurring inside the generation chamber and the condensation system.

The typical collection time of the fumes was 5 consecutive days. This long period permits collecting up to 10 $\mathrm{ml}$ of condensate for the most productive bitumen and $2 \mathrm{ml}$ on average for all the bitumens tested.

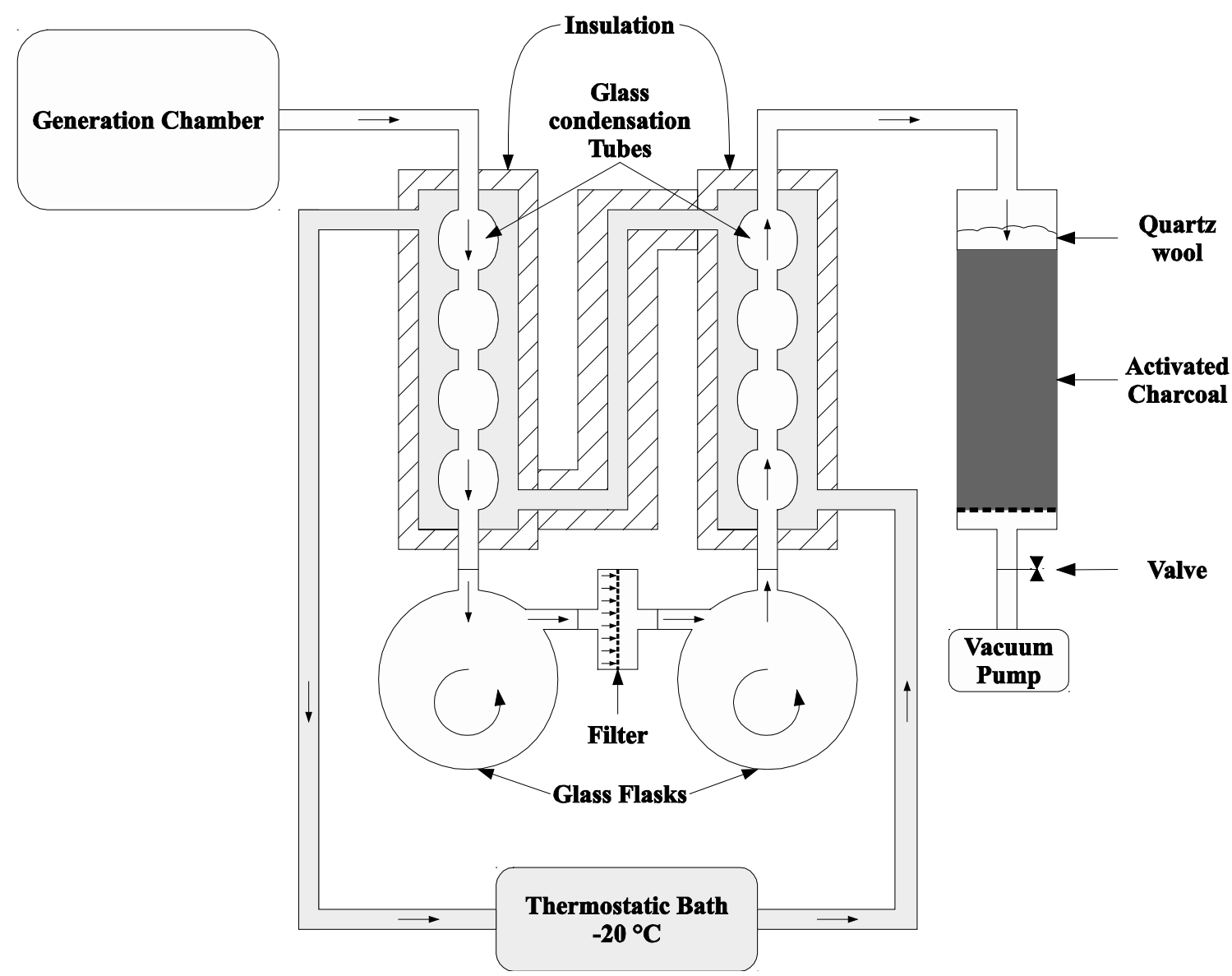

Figure 2. Schematic representation of the fume condensation system used for the study. 
At the end of the 5 days, the two tubes were washed with $20 \mathrm{ml}$ of $\mathrm{CH}_{2} \mathrm{Cl}_{2}$ (GPR RECTAPUR, VWR, ref. $23,367.365$, purity $=100 \%$ ) to dissolve all the organic material collected on the tube walls. The inner walls of the cassette and the filter were washed with $10 \mathrm{ml}$ of $\mathrm{CH} 2 \mathrm{Cl} 2$. After sonication of the filter, the extract was passed through a syringe filter (Chromafil. AO 45/25, Macherey-Nagel, ref. 729,013.400) to avoid any particu-

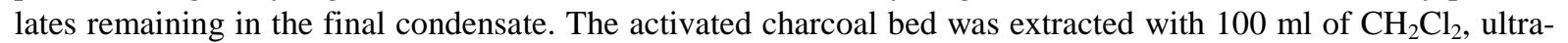
sonicated for $30 \mathrm{~min}$ and passed through the syringe filter. The extracts were finally merged to give a volume of $130 \mathrm{ml}$.

The $\mathrm{CH}_{2} \mathrm{Cl}_{2}$ of the merged extract was evaporated under a gentle flow of nitrogen. During evaporation, the extract was permanently homogenised to prevent the formation of a layer of viscous condensate at the surface liable to block the evaporation $\mathrm{CH}_{2} \mathrm{Cl}_{2}$. The nitrogen flow was stopped when the mass of the condensate, determined by a precision balance, did not change for $30 \mathrm{~min}$, preventing the loss of lightest compounds. As the evaporation of $\mathrm{CH}_{2} \mathrm{Cl}_{2}$ is endothermic and to maintain a constant evaporation speed, the vial was placed inside a thermostatic plate regulated at $30^{\circ} \mathrm{C}$.

Great care was taken to reduce the time needed for the total evaporation of $\mathrm{CH}_{2} \mathrm{Cl}_{2}$. Indeed, the volatile and semi-volatile compounds equivalent to $\mathrm{C}_{6}$ to $\mathrm{C}_{18} \mathrm{n}$-alkanes can also evaporate during $\mathrm{N}_{2}$ blowing. Finally, the bitumen fume condensate was conserved at $4^{\circ} \mathrm{C}$.

\subsection{Bitumen}

The bitumen used for the study was a 50/70 grade bitumen used for hot paving. It is the same bitumen as that used by Binet and Bonnet [7] and Vu Duc and Huynh [8] [9] in their studies, for which chemical characterization was performed.

\subsection{Measurement Methods}

An acquisition and data logger device (Ahlborn, Almemo MA26908A) centralized and acquired the signals from the sensors measuring the temperature of the bitumen, the relative pressure inside the generation chamber and the temperature and relative humidity inside the exposure chamber. The acquisition frequency was $1 \mathrm{~Hz}$ throughout the generation period.

The measurement were analysed for to check the stability and reproducibility of the generation conditions.

Airborne particles constituting the bitumen fumes were sampled inside the exposure chamber and detected by a Portable Aerosol Spectrometer (PAS) (GRIMM, Model 1.108). The PAS calculated the total particle concentration in number and mass, and the characteristics of the granulometry as the Mass Median Diameter (MMD) and the geometric standard deviation noted $\sigma_{g}$, for particle diameters ranging from 0.25 to $32 \mu \mathrm{m}$.

12 personal samplers can be placed inside the exposure chamber for homogeneity and quality tests. The samplers were the same as those used in the study by Sutter et al. [10]. They were designed with a 37 mm polystyrene closed-face cassette with a $4 \mathrm{~mm}$ orifice (Supelco Sigma Aldrich), containing a PTFE membrane with pores of $1 \mu \mathrm{m}$ (Membrane GelmanZefluor $1 \mu \mathrm{m}$ - $37 \mathrm{~mm}$, Supelco Sigma Aldrich), connected to an Amberlite ${ }^{\mathrm{TM}}$ XAD-2 400/200 mg sorbent tube (ORBO 609 400/200 mg XAD-2, Supelco Sigma Aldrich). The sampling flow was set to $1 \mathrm{l} \cdot \mathrm{min}^{-1}$. This device samples both the particulate and vapour phases of the bitumen fumes.

As recommended in the study by Sutter et al., n-heptane was used as the extraction solvent for both collection substrates (filter and XAD-2). The filter and XAD-2 were extracted separately in 4 ml n-heptane with mechanical agitation for $20 \mathrm{~min}$. and ultra-sonication for $1 \mathrm{~h}$.

Extracts were analysed by a Gas Chromatograph equipped with a Flame Ionization Detector (GC-FID) using a Shimadzu model GC-2010 Plus with helium as carrier gas at a constant speed of $40 \mathrm{~cm} \cdot \mathrm{s}^{-1} .2 \mu \mathrm{lof} \mathrm{sample}$ were injected into a split/splitless injector, and set at $280^{\circ} \mathrm{C}$ in splitless mode for 1 min. A non-polar capillary column, $30 \mathrm{~m} \times 0.32 \mathrm{~mm} \times 0.25 \mu \mathrm{m}$ (Zebron ZB-5HT, Phenomenex) was used. The oven temperature increase was programmed from $45^{\circ} \mathrm{C}$ (7.5 min) to $260^{\circ} \mathrm{C}$ at $100^{\circ} \mathrm{C} / \mathrm{min}$ and then held for $10 \mathrm{~min}$. The FID detector was set at $350^{\circ} \mathrm{C}$ using an acquisition frequency of $50 \mathrm{~Hz}$. This chromatographic method forced the bitumen fume compounds to separate from the n-heptane and to collapse into a single massive peak from which the area was calculated by integration. The method was calibrated with n-hexadecane $\left(\mathrm{C}_{16}\right)$.

\subsection{Field Sampling}

The similarity of the fumes generated with the two configurations presented previously was studied, regarding 
the quality and the granulometry of the particles. Laboratory samples and a condensate were compared to samples taken from pavement construction sites. The field samples were only taken from construction sites where hot 35/50 grade bitumens were used. 13 field samples were analysed according to the MetroPol M-2 method [11], similar to that described previously in this paper, with the exception of the collection substrate desorption step for which the substrates were placed and extracted simultaneously in the same vial. Then the chromatograms where compared with those of the laboratory samples.

\section{Results and Discussions}

\subsection{Stability of Fume Generation}

Figure 3 presents the typical evolution of the direct reading parameters over a full day of generation with 3 sampling times. The graphs represented in Figure 3 are divided into 7 events:

- 1: stabilisation of the generation before sampling.

- 2, 4 and 6: sampling period.

- 3 and 5: opening of the door to replace used samplers with new blank ones.

- 7: end of generation and opening of the chamber.

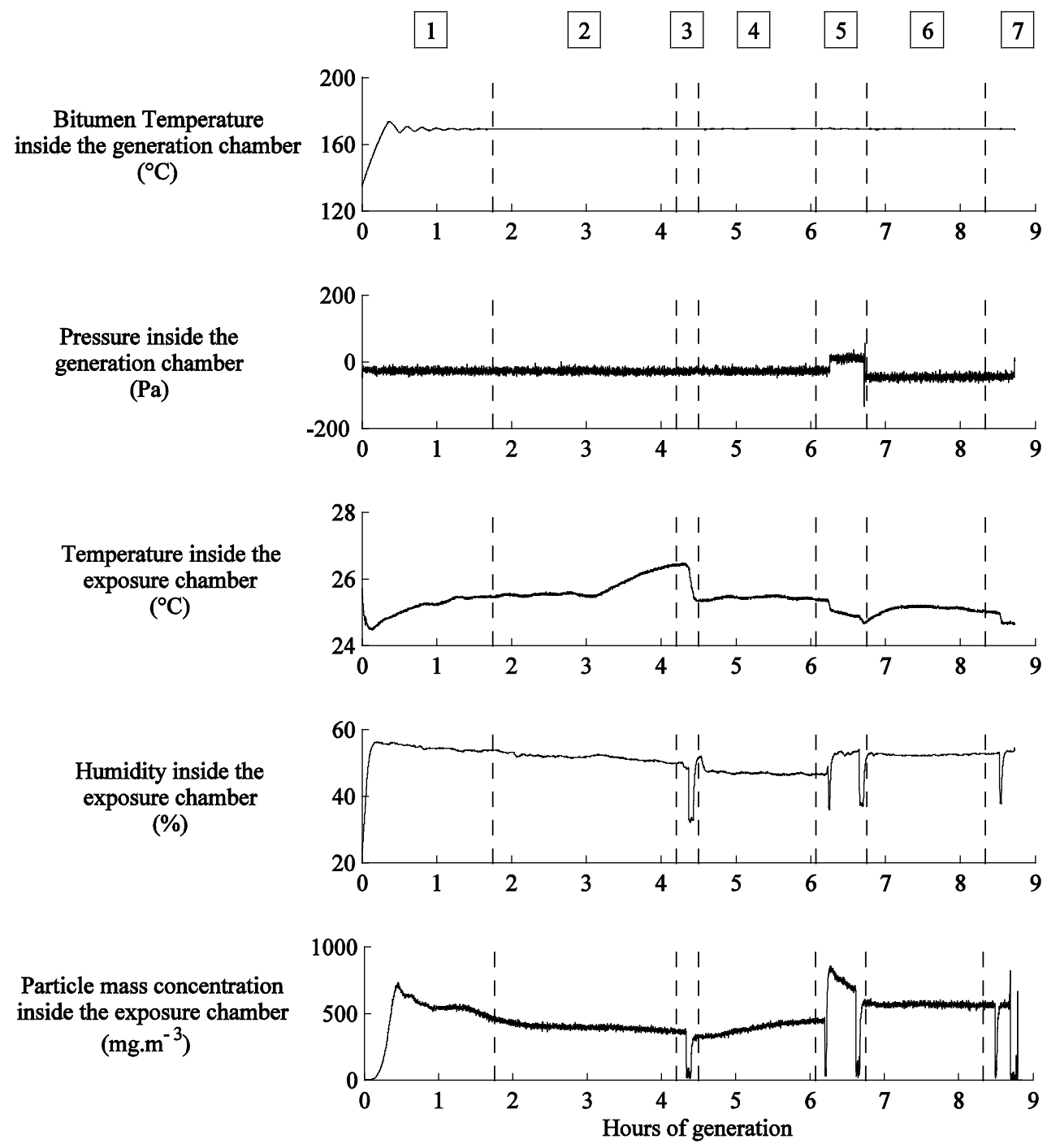

Figure 3. Typical evolution of temperatures, pressure, humidity and particle mass concentration during a generation. 
During the stabilisation step noted 1 , the bitumen was heated and stabilized at $170^{\circ} \mathrm{C}$ within 1 hour. A particle mass concentration peak was generated during this period, certainly due to the slight over-heating of the bitumen during the first 30 minutes of heating. This phenomenon was also observed in previous studies [12] [13], proving that it is a reproducible behaviour. Although the bitumen temperature was stabilized within 1 hour, an additional period of 45 minutes was necessary to stabilize the particle concentration and the temperature inside the exposure chamber.

The humidity was quickly stabilized within 15 minutes, corresponding to the time needed for the thermostatic water bath to heat the humidifier to $60^{\circ} \mathrm{C}$. The pressure inside the generation chamber was stabilized directly and was not influenced by the temperature of any part of the generation system. The sampling periods are identified as steps 2, 4 and 6 in Figure 3. It was essential to produce reproducible generations during these periods.

The regulation of the bitumen temperature is very stable and well-adjusted regarding the standard deviation (STD) and Min-Max Values. The STD calculated on the internal pressure of the generation chamber demonstrated that perturbations had occurred during the sampling period without acting on the other parameters. Inside the exposure chamber, the temperature and humidity were shown to be stable. The relative humidity ranged from $21.6 \%$ to $80.2 \%$.

The total particle mass concentration calculated by the PAS ranged from 0.01 to $9.36 \mathrm{mg} \cdot \mathrm{m}^{-3}$. The MMD of the particles generated inside the exposure chamber varied from 1.25 to $6.17 \mu \mathrm{m}$, with a median value of 2.58. The geometric standard deviation $\sigma_{g}$ of the granulometry ranged from 1.34 to 2.10, with a median value of 1.50 . Very few data are available in the literature on the granulometry of bitumen fume particles in workplaces. Field measurements have shown that $96 \%$ to $99.7 \%$ of the particle mass is below $12.5 \mu \mathrm{m}$ [14] [15] and between 0.72 and $1.19 \mu \mathrm{m}$ for an MMD with $\sigma_{g}$ ranging from 1.98 to 2.17 in the study of Herrick and McClean [16]. Therefore, the granulometry generated by the present system was consistent with the published data.

\subsection{Homogeneity}

The homogeneity of the aerosol inside the chamber was evaluated by quantifying particles and vapours collected on all the substrates of the samplers simultaneously exposed to the aerosol. For all the generations, the STD calculated on the total mass of aerosols (particles + vapours) of each generation was equal to $3 \%$. Consequently, the exposure chamber ensured good homogenisation of the aerosol in the entire volume of the chamber and could simultaneously expose up to 12 samplers to the same aerosol.

\subsection{Repeatability of the Fume Generation}

3 generations were reproduced under the same conditions on 3 different days, with bitumen batches used each time for the first time. The particle concentration profiles of the 3 generations are presented in Figure 4. Discrepancies can be seen between the 3 particle concentration profiles. The STD calculated on the 3 generations was $31.7 \%$. Although great care was taken to stabilize the generation before sampling the fumes, there is still a difference between the generations in term of particle concentrations.

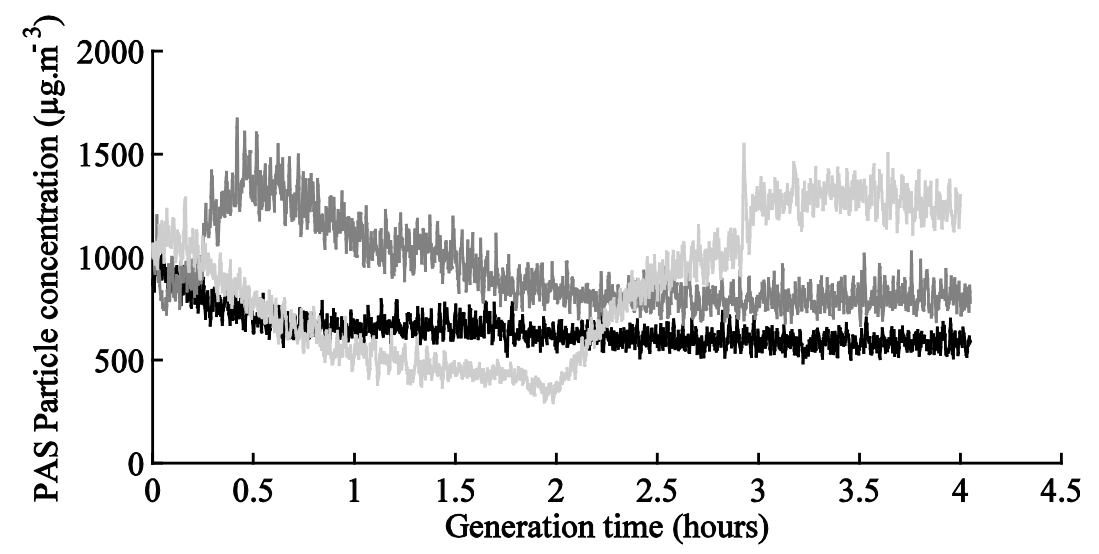

Figure 4. PAS particle concentration profiles obtained for 3 generations of fumes from 3 new batches of the same bitumen. 
In contrast, the MMD is much more reproducible with an average value of $2.76 \mu \mathrm{m}$ associated with an STD of $4.7 \%$ over the 3 generations. In addition, the granulometry is characterised by an average $\sigma_{g}$ of 1.51 with a STD of $0.8 \%$. These results show that even if the particulate concentration varied slightly for each generation, the characteristics of the granulometry did not change and were reproducible.

Figure 5 presents the chromatograms produced by the analysis of the filters and XAD2 beds of a sampler exposed to each of the 3 fumes emitted from the previous 3 identical generations. The organic matter emitted by the bitumen fumes ranged from $\mathrm{C}_{9}$ to $\mathrm{C}_{30}$ equivalent n-alkane with a retention time (RT) from 7 to 20 min. Qualitatively, no significant differences were observable for the organic matter collected on the filters and on XAD2 as a function of the generation replicate. Quantitatively, the average quantity analysed on the filters was $0.44 \mathrm{mg} \cdot \mathrm{m}^{-3}$, with a standard deviation of $13.6 \%$. On the XAD2 bed, the average quantity was $0.43 \mathrm{mg} \cdot \mathrm{m}^{-3}$ with an STD of $8.7 \%$. Thus the total quantity, the sum of the filter and XAD2 quantities, was determined at 0.87 $\mathrm{mg} \cdot \mathrm{m}^{-3}$ with an STD of $7.6 \%$. This demonstrates that the quantity of bitumen fumes generated on 3 different days under the same conditions is reproducible qualitatively and quantitatively.

\subsection{Aging of a Bitumen during Generation Time}

Because the generation method was applied in batch mode, compounds that were emitted into the fumes during the generation period induced the depletion of the bitumen in those compounds. Consequently, a change in the quality of the fumes as the bitumen got older was expected.

Bitumen fumes were sampled at sampling times of 14, 21, 32, 37 and $43 \mathrm{~h}$ of generation. This duration included different days of generation and therefore multiple phases of heating and cooling between room temperature and $170^{\circ} \mathrm{C}$. The quality of the fumes was observed by comparing the chromatograms of filters and

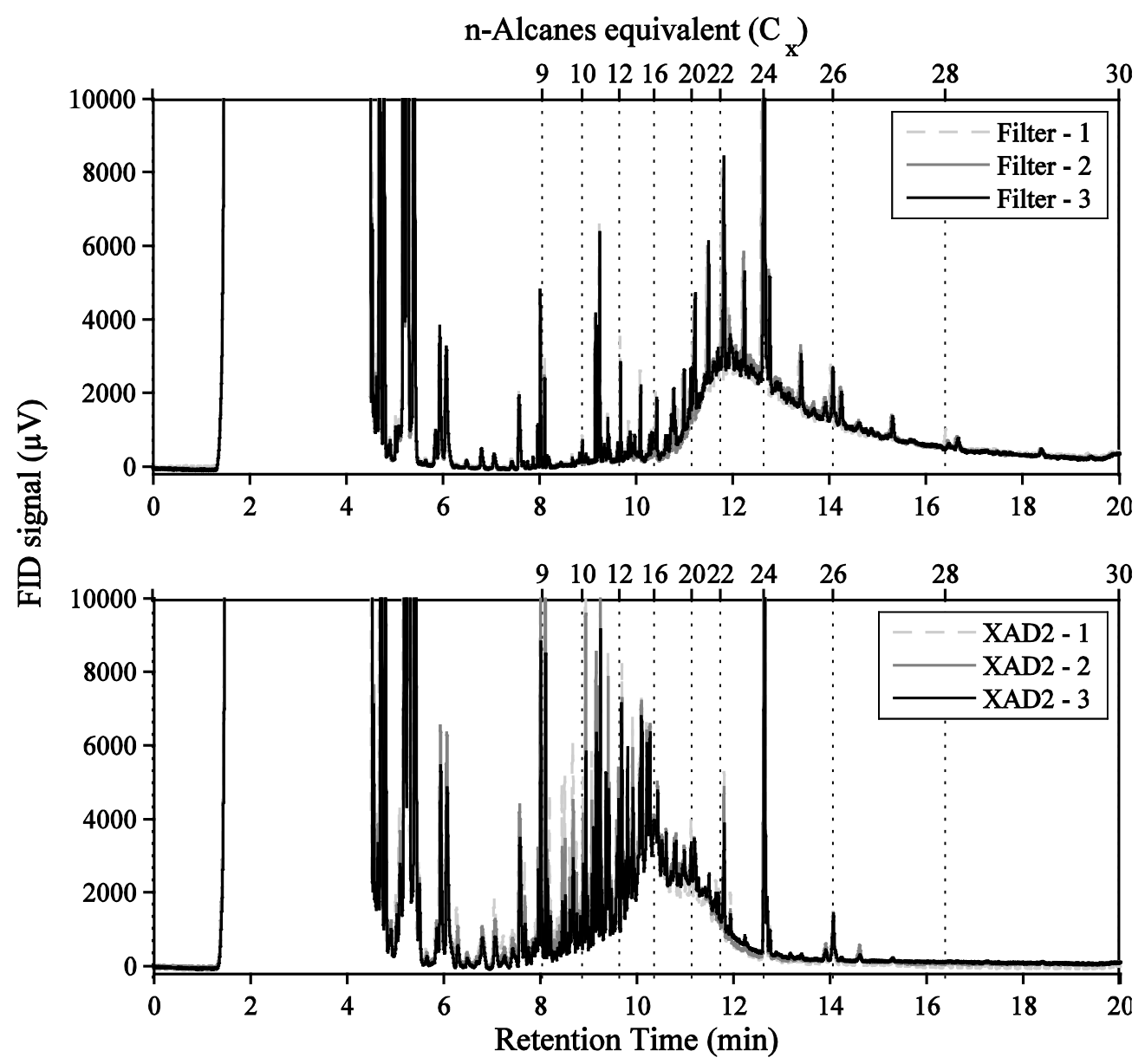

Figure 5. Chromatograms of extracted filters and XAD2 for the 3 replicates of generation. 
XAD2 extracts, normalized for strict comparison. The normalization consisted in equalizing the areas developed under the curves of all the chromatograms from an RT of 7 to $12 \mathrm{~min}$.

The filter chromatograms were the same from the first sample taken at $14 \mathrm{~h}$ of generation and the last at $43 \mathrm{~h}$. In contrast, the chromatograms of the XAD2 extract showed differences as a function of the age of the bitumen. Figure 6 presents these differences by comparing the chromatogram of the first sample with samples taken at different times. The translation of the shape of the compounds from an RT shorter than 9 min to an RT after 10 min can be seen. The lightest compounds equivalent to $C_{8}$ to $C_{10} n$-alkanes produced smaller peaks as the generation time increased. This is evidence that bitumen is depleted in light compounds as its age increases. The lightest compounds were replaced by heavier ones, equivalent to $\mathrm{C}_{14}$ to $\mathrm{C}_{20} \mathrm{n}$-alkanes. The augmentation of the heavier compounds was due to the adaptation of $Q_{f}$ to produce the same concentration.

After 11 min. RT, the chromatograms were very similar regardless of the age of the bitumen. This phenomenon is explained by the fact that the compounds having an RT longer than 11 min, equivalent to $C_{20}$ and more n-alkanes, were mostly collected on the filter. As there was no difference between any of the chromatograms of filter extracts, this demonstrates that heavier compounds above $\mathrm{C}_{20}$ equivalent n-alkane are emitted slowly from the bitumen, inducing a constant emission of fumes over the $43 \mathrm{~h}$ of generation.

In brief, the aging of the bitumen had no effect on the quality of the fraction of the organic compounds collected on the filters, equivalent to $\mathrm{C}_{20}$ and above n-alkanes. In contrast, an aging effect could be observed on the quality of the fraction of organic compounds collected on the XAD2 bed, equivalent to $\mathrm{C}_{12}$ and below n-alkanes. Consequently, a batch of bitumen should not be used for generation exceeding a generation time of 30 hours, since the quality of the fumes can vary significantly for the more volatile compounds.
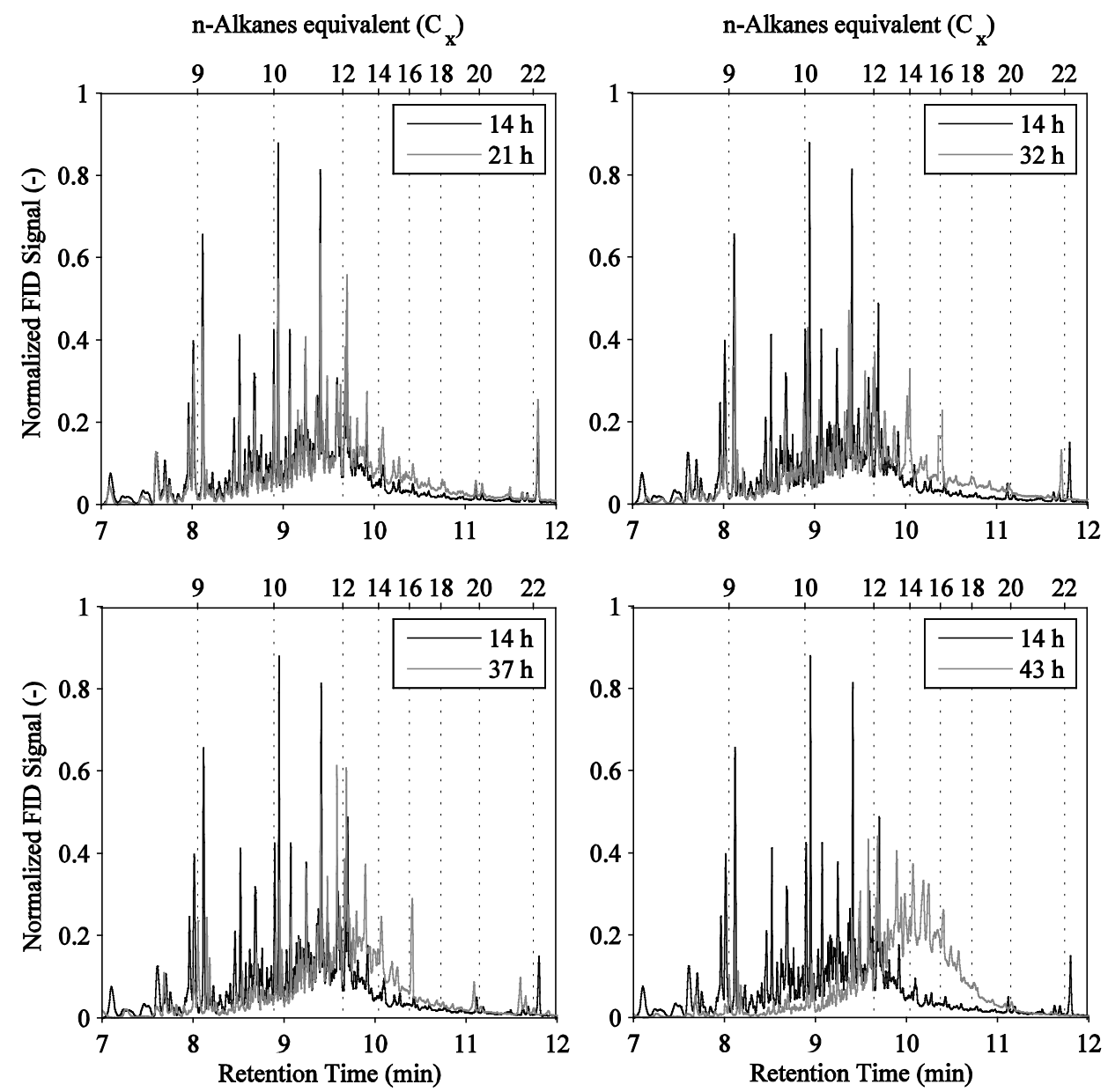

Figure 6. Chromatograms of XAD2 extract as a function of the age of the bitumen used for the generation. 


\subsection{Field Similarity}

The chromatograms of a sample in the exposure chamber were compared to 13 field samples. Because the mass of compounds collected on each sampler was different, relative cumulated curves were calculated from the chromatograms and are shown in Figure 7. The field samples had different profiles characterized by a median retention time (MRT) and a median n-alkane equivalent (MAE) ranging from 9.5 to 10.5 min and $\mathrm{C}_{11}$ to $\mathrm{C}_{16}$, respectively. The RT of $80 \%$ had a greater range from 10 to 11.5 min., corresponding to $\mathrm{C}_{14}$ to $\mathrm{C}_{21} \mathrm{n}$-alkanes.

Although the bitumens were used on hot paving construction sites, it was clearly demonstrated that the quality of the fumes generated in the air of the workplace differed as a function of the construction site and more particularly of the origin and pre-treatment of the bitumen used.

The comparison of the field samples to laboratory samples shows that the curve of the XAD2 chromatogram is similar to the field chromatograms with an MRT of $10.5 \mathrm{~min}$ and an MAE of $\mathrm{C}_{16}$. In contrast, the organic matter collected on the filter had a longer RT than that of the field sample with an MRT of 12.5 min, MAE $\mathrm{C}_{23}$. Thus the compounds collected on the filter in the laboratory system were less volatile than those collected in the field.

This difference in fume quality regarding the MRT and MAE can be explained by the difference in the nature and grade of the bitumens used for the generation in the laboratory and at the workplace.

\subsection{Characterisation of the Condensation System}

Figure 7 presents a comparison of cumulated curves calculated for the 13 field samples and the condensate generated by the condensation system. A slight difference can be seen between the field samples and the condensate for which the MRT was 11 min and the MAE was $\mathrm{C}_{20}$. The differences in nature and grade identified previously for the bitumen used in the laboratory and those used at workplaces could explain most of the gap observed.

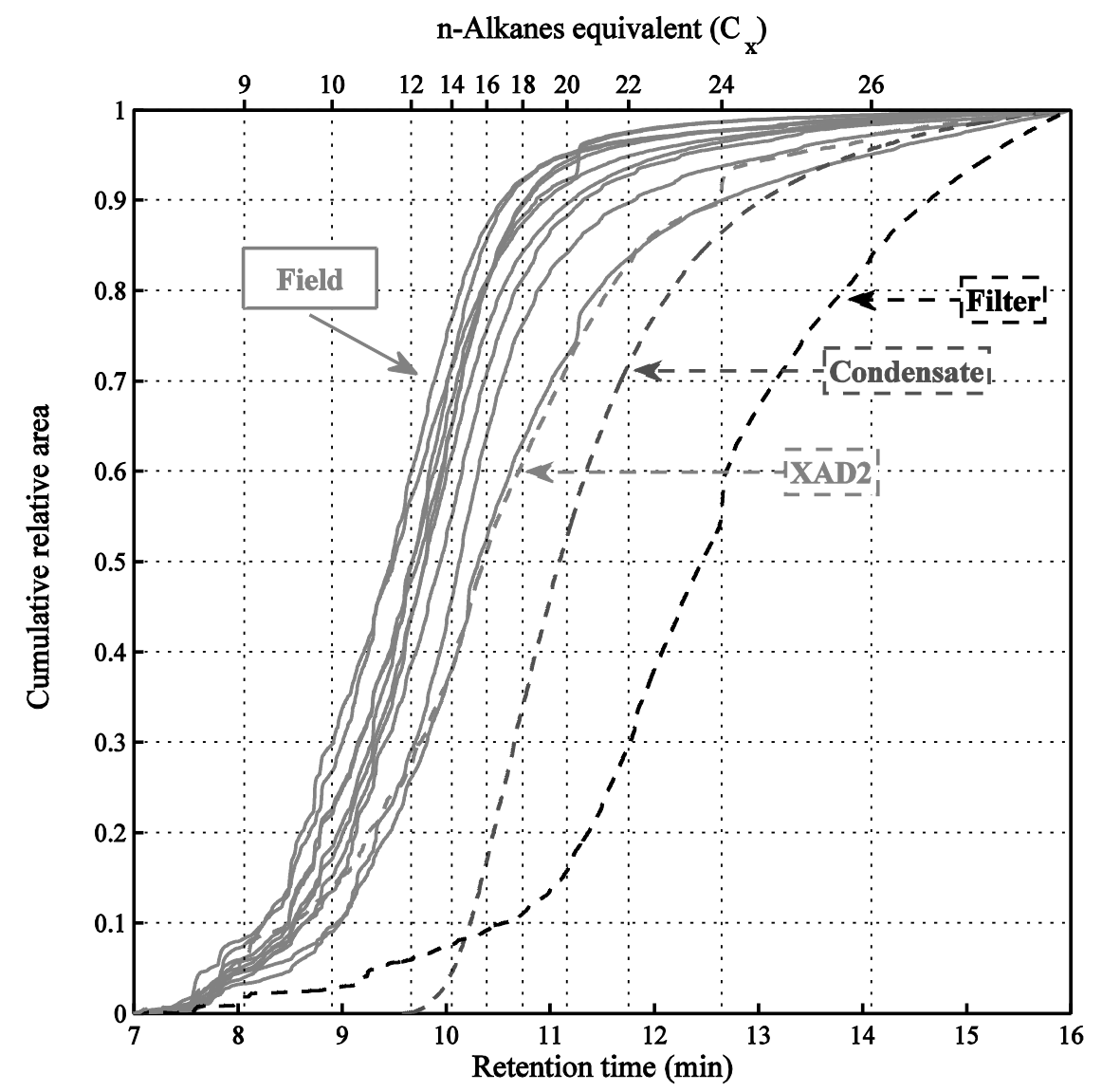

Figure 7. Cumulated relative curves calculated from laboratory and field samples. 
The condensate curve was included between the two cumulated curves of the filter and the XAD2, except for the first $10 \%$ of the compounds which were not present in the condensate whereas they were in the sample emitted in the exposure chamber. The missing compounds are the most volatile of the bitumen fumes generated by the system, equivalent to n-alkanes below $\mathrm{C}_{14}$. Thus $90 \%$ of the fumes were correctly collected by the condensation system. It is very likely that during the evaporation of the $\mathrm{CH}_{2} \mathrm{Cl}_{2}$ from the activated charcoal extract, the lightest compounds, below $\mathrm{C}_{14}$ equivalent n-alkane, evaporated simultaneously with the solvent, leading to the under representation of those light compounds in comparison to the compounds equivalent to $\mathrm{C}_{14}$ and above.

\section{Conclusions}

A new bitumen fume generation system was developed for future sampling and analytical methods intended to assess the exposure of workers in the workplace. This study evaluated the performances of this system in two configurations: the generation of fumes for the direct exposure of personal samplers tested in an exposure chamber and the generation of a bitumen fume condensate.

The results demonstrated that the fumes generated for direct exposure in the exposure chamber were stable, reproducible and could cover a wide range of humidities and concentrations. Humidity varied from $22 \%$ to $80 \%$ $\mathrm{RH}$ and the particle concentrations varied from 0.01 to $9.36 \mathrm{mg} \cdot \mathrm{m}^{-3}$, allowing the development of sampling methods according to EN 13936 [6].

The exposure chamber was well homogenised under all generation conditions, with a median variation coefficient of $3 \%$ on the total concentration determined by 12 samplers placed simultaneously inside the chamber.

The MMD of the fume particles varied from 1.25 to $6.17 \mu \mathrm{m}$. The granulometry was slightly polydispersed with a $\sigma_{g}$ ranging from 1.34 to 2.10 . These results agreed very well with the field measurements, demonstrating the capacity of the system to produce laboratory fumes physically identical to those in the field.

Aging and dilution effects on the quality of the fumes generated were identified. Generation prior to $30 \mathrm{~h}$ was qualitatively constant, which was not the case for longer times due to the significant depletion of compounds lighter than the equivalent $\mathrm{C}_{12} \mathrm{n}$-alkane. The airflow inside the generation chamber had effects on fume granulometry in terms of MMD and $\sigma_{g}$, and on the distribution of organic matter inside the personal sample used. Consequently, the quality of a fume generated inside the system varied as a function of quantity. This behaviour was attributable to the semi-volatility of the compounds of the bitumen fumes.

The similarity of the fumes generated in the system was evaluated by comparing fumes generated with a 50/70 bitumen in the system with 13 independent field samples from French road paving worksites. The results showed that the fumes were comparable but not strictly identical as the grades of the bitumens used for the laboratory generation and in the field had were not the same.

The system developed in this study could be used for developing sampling methods according to the EN 13936 standard. Furthermore, the system is able to generate fume condensates of high quality, thereby facilitating the development of new analytical methods. Since the fumes generated in the system were not strictly identical to those generated in the workplaces, the development of the methods used for sampling and analysing bitumen fumes must be confirmed under real conditions.

\section{Acknowledgements}

The authors would like to thank the French Union of Bitumen Producers (Groupement Professionnel des Bitumes, GPB) for having generously provided the bitumen sample used in this study. The authors would also like to thank the members of the trade unions of the French Road Industry (Union des Syndicats de l'Insdustrie Routière Française, USIRF) for providing access to road paving construction sites for the field samplings.

\section{References}

[1] IARC (2013) Bitumens and Bitumen Emissions, and Some N- and S-Heterocyclic Polycyclic Aromatic Hydrocarbons. IARC Monographs, 103. https://monographs.iarc.fr/ENG/Monographs/vol103/mono103.pdf

[2] Butler, M., Burr, G., Dankovic, D., Lunsford, R., Miller, A., Nguyen, M., Sharpnack, D. and Olsen, L. (2000) Hazard Review: Health Effects of Occupational Exposure to Asphalt. Report Number: DHHS/PUB/NIOSH-2001-110 154, 154. www.cdc.gov/niosh/docs/2001-110/pdfs/2001-110.pdf

[3] ACGIH (2001) Asphalt (Bitumen) Fumes (\#7 DOC-041). ACGIH-TLV Chemical Substances 7th Edition Documentation. 
[4] Breuer, D. (2008) Bitumen (Daempfe und Aeorosole, Mineralöl-Standard). BGIA Method 6305-1 Berlin, Erich Schmidt. BGIA Working Folder.

[5] CEN (2012) EN 482-Workplace Exposure-General Requirements for the Performance of Procedures for the Measurement of Chemical Agents. Brussels.

[6] CEN (2012) EN 13936-Workplace Exposure-Procedures for Measuring a Chemical Agent Present as a Mixture of Airborne Particles and Vapour. Requirements and Test Methods. Brussels.

[7] Binet, S., Bonnet, P., Brandt, H., Castegnaro, M., Delsaut, P., Fabries, J.F., Huynh, C.K., Lafontaine, M., Morel, G., Nunge, H., Rihn, B., Duc, T.V. and Wrobel, R. (2002) Development and Validation of a New Bitumen Fume Generation System Which Generates Polycyclic Aromatic Hydrocarbon Concentrations Proportional to Fume Concentrations. Annals of Occupational Hygiene, 46, 617-628. http://dx.doi.org/10.1093/annhyg/mef081

[8] Vu-Duc, T., Huynh, C.K., Lafontaine, M., Bonnet, P. and Binet, S. (2002) A Spectrophotometric Method for the Determination of Organic Soluble Matter in Bitumen Fumes. Applied Occupational and Environmental Hygiene, 17, 495500. http://dx.doi.org/10.1080/10473220290035732

[9] Vu-Duc, T., Huynh, C.-K. and Binet, S. (2007) Laboratory Generated Bitumen Fumes under Standardized Conditions. Clean-Up Scheme and Ion Trap GC-MS Analysis of VOC, Semi-Volatile and Particulate PAH and PASH. Journal of Occupational and Environmental Hygiene, 4, 245-248. http://dx.doi.org/10.1080/15459620701274382

[10] Sutter, B., Ravera, C., Hussard, C. and Langlois, E. (2015) Alternatives for Benzene in the Extraction of Bitumen Fume from Exposure Sample Media. Annals of Occupational Hygiene, 60, 101-112. http://dx.doi.org/10.1093/annhyg/mev068

[11] INRS (2015) MetroPol Method M-2: Fumées de bitume par chromatographie en phase gazeuse-Bitumen fumes by gaseous chromatography. Placed Published. http://www.inrs.fr/publications/bdd/metropol/fiche.html?refINRS=METROPOL_2

[12] Gaudefroy, V., Viranaiken, V., Paranhos, R., Jullien, A. and de La Roche, C. (2010) Laboratory Assessment of Fumes Generated by Bituminous Mixtures and Bitumen. Road Materials and Pavement Design, 11, 83-100. http://dx.doi.org/10.1080/14680629.2010.9690261

[13] Jullien, A., Gaudefroy, V., Ventura, A., de La Roche, C., Paranhos, R. and Monéron, P. (2010) Airborne Emissions Assessment of Hot Asphalt Mixing Methods and Limitations. Road Materials and Pavement Design, 11, 149-169. http://dx.doi.org/10.3166/rmpd.11.149-169

[14] Brandt, H.C. and de Groot, P.C. (1999) A Laboratory Rig for Studying Aspects of Worker Exposure to Bitumen Fumes. American Industrial Hygiene Association Journal, 60, 182-190. http://dx.doi.org/10.1080/00028899908984433

[15] Calzavara, T.S., Carter, C.M. and Axten, C. (2003) Applied Occupational and Environmental Hygiene Air Sampling Methodology for Asphalt Fume in Asphalt Production and Asphalt Roofing Manufacturing Facilities: Total Particulate Sampler versus Inhalable Particulate Sampler Air Sampling Methodology for Aspha. Applied Occupational and Environmental Hygiene, 18, 358-367. http://dx.doi.org/10.1080/10473220301366

[16] Herrick, R.F., McClean, M.D., Meeker, J.D., Zwack, L. and Hanley, K. (2007) Physical and Chemical Characterization of Asphalt (Bitumen) Paving Exposures. Journal of Occupational and Environmental Hygiene, 4, 209-216. http://dx.doi.org/10.1080/15459620701334806 